U. S. Department of the Interior

Geological Survey

Water Resources Division

Washington, D. C.

\title{
AN AUTOMATIC SUSPENDED-SEDIMENT SAMPLER
}

Byy James C. Mundorff

$57-80$

Open File Report

Prepared by Quality of Water Branch - October 1957 


\title{
AN AUTOMATIC SUSPENDED-SEDIMENT SAMPLER
}

\author{
By James C. Mundorff
}

The automatic suspended-sediment sampler was originally designed to obtain a suspendedsediment sample from a single point in a stream or reservoir during a rise in stage. The sampler was intended to be used during periods when manually-operated standard samplers could not be used. If the sampling site is remote from the field office or is inaccessible during storm periods or if no notification can be obtained concerning a stream rise, an adequate sampling program may be difficult to maintain. Having full knowledge of the many limitations and inadequacies of this automatic sampler, personnel of several of the Quality of Water Branch offices believe that, for many types of sediment transport and for specific sampling sites, samples obtained with the automatic sampler are preferable to a complete lack of samples.

The sampler is somewhat similar to the Gluschkoff sampler described on page 152 , Federal Interagency Report No. 1, Field practice and equipment used in sampling suspended sediment. An automatic sampler was first used by the Geological Survey in the Austin, Tex. , office in 1954. The design, operation, and dependability of the sampler discussed herein were improved by suggestions by personnel of the offices at Lincoln, Nebr., Worland, Wyo., Norton, Kans., and Rapid City, S. Dak.

Criteria for automatic samplers for use in the Lincoln area were (1) rapid fabrication of an inexpensive fixed sampler that would obtain a suspended-sediment sample from near the stream surface and at an intake velocity somewhat similar to stream velocity, and (2) incorporation into the sampler of a simple mechanism to isolate the sample from contamination while submerged.

The sampler consists essentially of a pint milk bottle, a no. 8 rubber stopper, an intake tube, and an exhaust tube (figs. 1-5). Variations may be made in the length, diameter, and shape of the intake and exhaust tubes; in the use of one-way or two-way shutoff valves for the exhaust tube; in the use of an automatic closure on the intake tube; in the direction in which the intake and exhaust tubes are oriented relative to streamflow;. and in the type of debris shield, if any, that is placed in front of the samplers. Variations in sampler construction and mounting are dependent on local conditions at the selected sampling site.

The automatic sampler is mounted in a fixed position relative to stream stage, and the sampler bottle fills to a predetermined level as the water level rises past the uncalibrated sampler intake opening.

For automatic sampling in stockponds or in very low-velocity streams, the original sample will generally remain uncontaminated during submergence if the intake and exhaust tubes are of the approximate shape and length shown in figure 1 . The use of exhaust valves may be unnecessary in still water.

If stream velocities of more than one foot per second are expected, certain measures should be taken to prevent enrichment or depletion of the sediment in the original sample. Circulation and/or diffusion may alter the concentration and particle-size distribution of the original sample. The Lincoln office has had considerable success in the use of a one-way valve (Davol No. 1940) to prevent circulation of water through the sample bottle during periods of sampler submergence. A single valve placed on the bottom of the exhaust tube inside the bottle (figs. 1-2) will generally prevent circulation during submergence. A float in the 


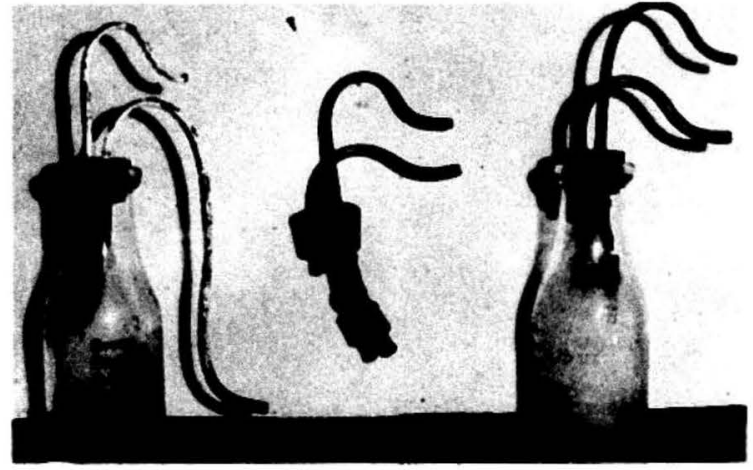

Figure 1. --Automatic suspendedsediment samplers.

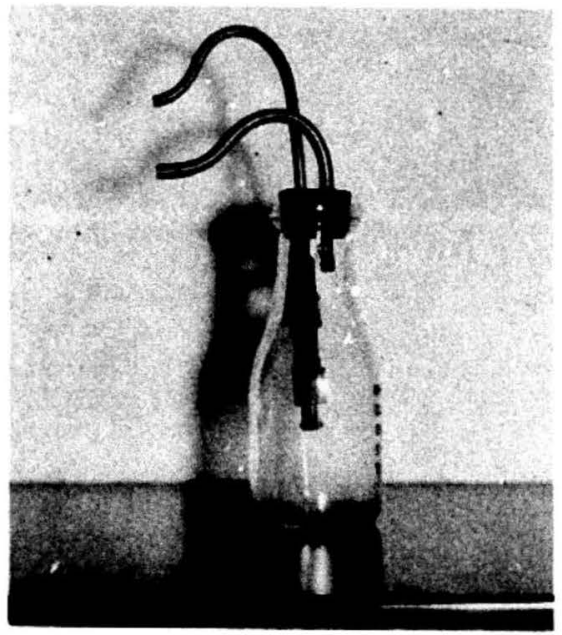

Figure 3. --Automatic sampler having two valves on the exhaust.

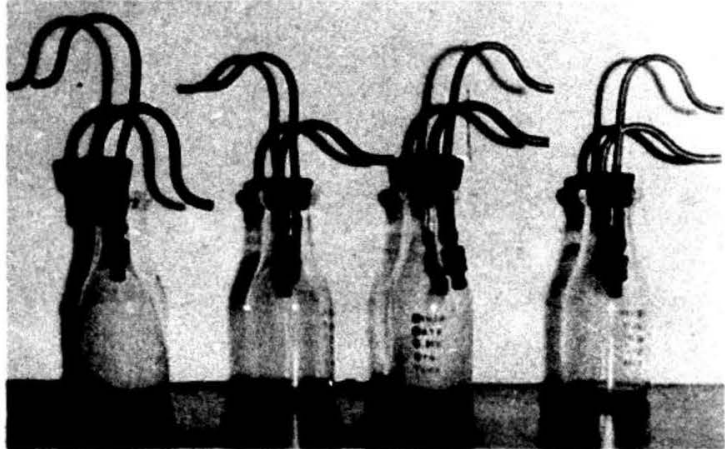

Figure 2. --Nozzle and exhaust variations on automatic samplers.

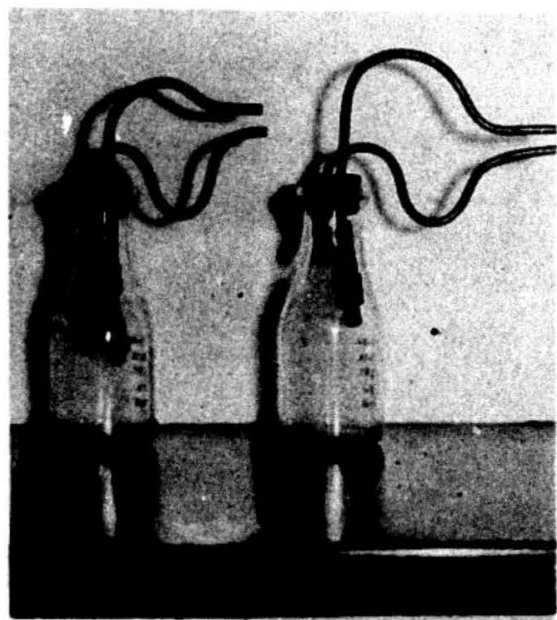

Figure 4. --Trap-type intake tube on automatic samplers.

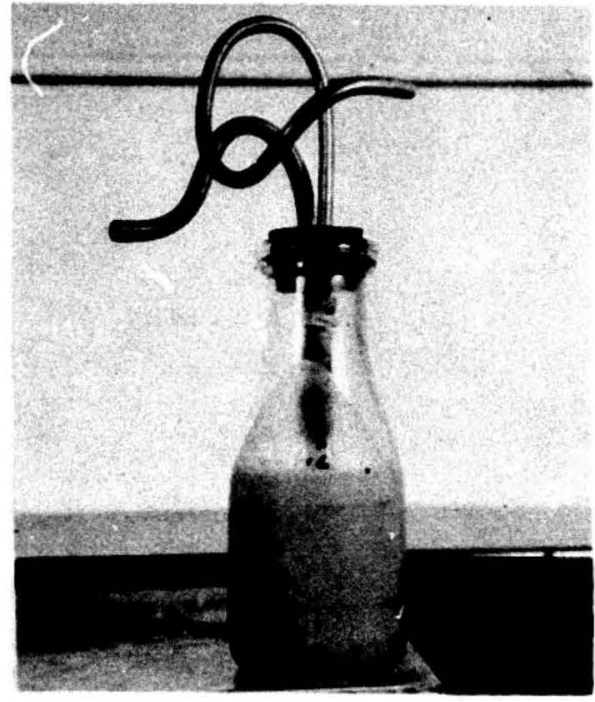

Figure 5. --Intake-exhaust arrangement on which exhaust faces downstream. 
valve is lifted into a closed position when the water level inside the bottle reaches the valve, and the flow of water into the bottle is stopped almost immediately. For extreme velocities or turbulence, a second valve is placed above the first valve (fig. 3 ). The valves are oriented so that the lower valve will be closed by an upward force and the upper valve will be closed by a downward force. The two valves prevent water. from entering the bottle through the exhaust tube and from rising into the exhaust tube. The end of the intake tube inside the bottle is slightly bent so that the water from the intake tube does not flow over the exhaust valve. The valve may not function properly if water and sediment enter the lower end of the valve while air is being exhausted from the bottle.

Most automatic samplers in the Lincoln area have had horizontal intake nozzles that are oriented into the streamflow. If an exhaust valve is used, the orientation of the exhaust is not of particular importance; however, the shutoff valve may give more positive closure if the intake is oriented into the flow and the exhaust is oriented away from the flow. (See the two samplers on the left in fig. 2). The orientation will result in a greater pressure at the intake opening than at the exhaust opening. The net force will thus be directed toward the valve and will give a firm closure.

If the intake and exhaust openings both face into the flow and are close together (fig. 4), circulation should not occur after total submergence because the static and velocity heads on both the intake and exhaust openings are about equal. However, under conditions of extreme turbulence and nonuniform flow, shutoff valves serve as an added safeguard against circulation between streamflow and sample.

The intake-exhaust arrangement shown in figure 5 will generally result in intake velocities equal to or greater than stream velocities. The elevation of the exhaust opening should be at the same elevation or slightly lower than the highest point on the intake tube so that the exhaust will be submerged during sampling. The exhaust opening faces away from the flow and is submerged during the sampling. During sampling, a lesser pressure at the exhaust than at the intake will cause the intake velocity to equal or exceed the stream velocity. The type of sampler shown in figure 5 will not function properly in still water and should be used only to sample streams having appreciable velocity.

The automatic samplers used in the Lincoln area have curved intake and exhaust tubes as shown in figures 1-5. The tubes are constructed of copper tubing having one-fourth inch, fivesixteenths inch, or three-eighths inch outside diameter. The intake tube is not necessarily of the same diameter as the exhaust tube. The radius of the curvature of the tubes varies from 1 to 2 inches. Although the velocity within the intake tube is not necessarily the same as the velocity of the stream, intake velocities are assumed to be most nearly correct when the nozzle is in a horizontal position and is exposed directly to stream velocities. Both tubes are curved so that sediment deposited in the end of the tubes during submergence will not fall into the sample bottle.

Emphasis should be placed on the fact that intake velocity may be less than, equal to, or greater than the stream velocity at the time of sampling. The relation of intake velocity to stream velocity will depend on whether the sampler is mounted in still water or in flowing water, whether the sampler is mounted behind a shield or in open flow, whether the intake faces into or away from the flow, whether the exhaust outlet is submergent or emergent at the time of filling, and whether, if submerged, the exhaust outlet faces into or away from the flow. The elevation of the exhaust outlet relative to the intake opening will also affect the intake velocity.

Methods of mounting the samplers may vary considerably. Two types of mountings are shown in figures 6-9. Figures 6 and 7 show the sampling installation currently in use in a stockpond near Syracuse, Nebr. The debris shield is of perforated sheet metal that is hinged along one side. This type of shield is used only in still water. Figures 8 and 9 show the "open" type of debris shield in use at the Little Blue River near Endicott, Nebr. The iron "bumpers" 


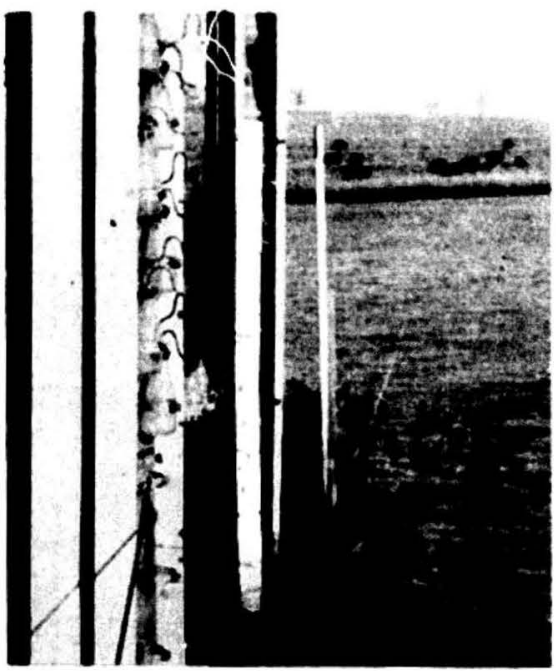

Figure 6. --Automatic sampler shield in open position.

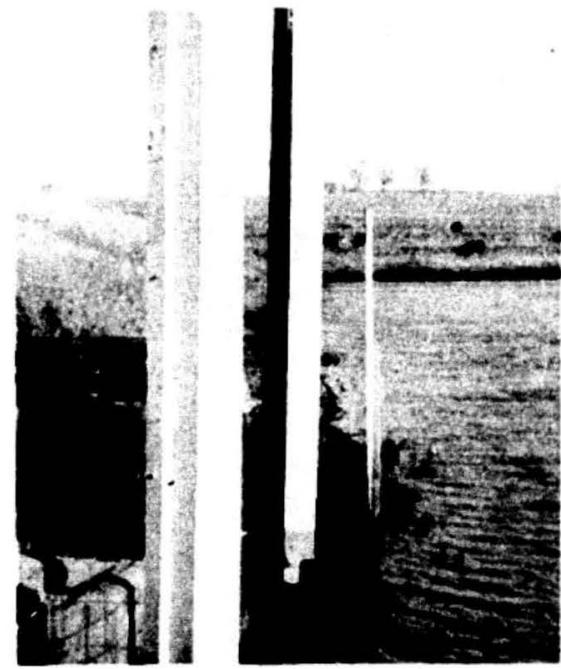

Figure 7. --Automatic ampler shield in closed position.

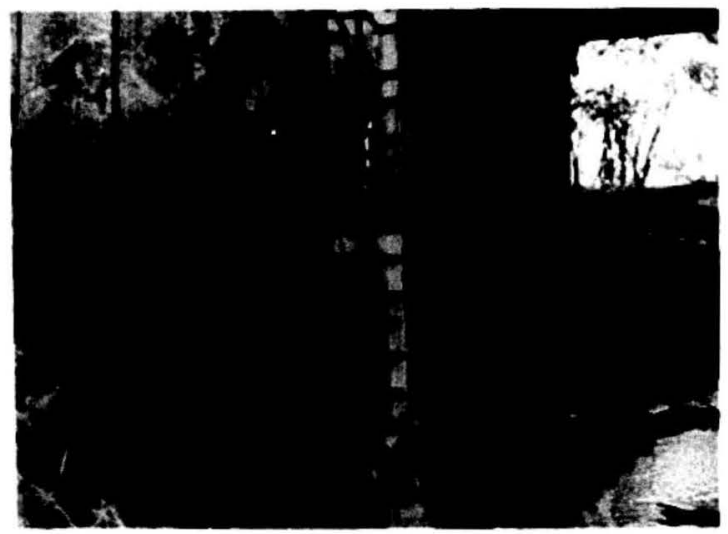

Figure 8. --Front view of the "open type of automatic sampler shield.

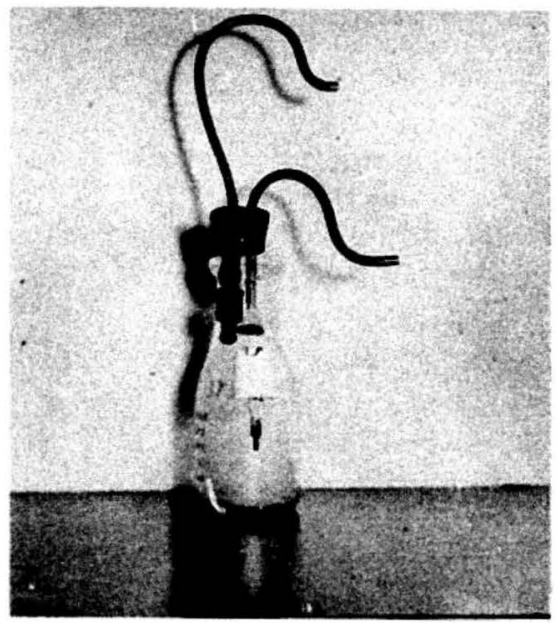

Figure 10. --Magnetic closure in open position on intake tube.

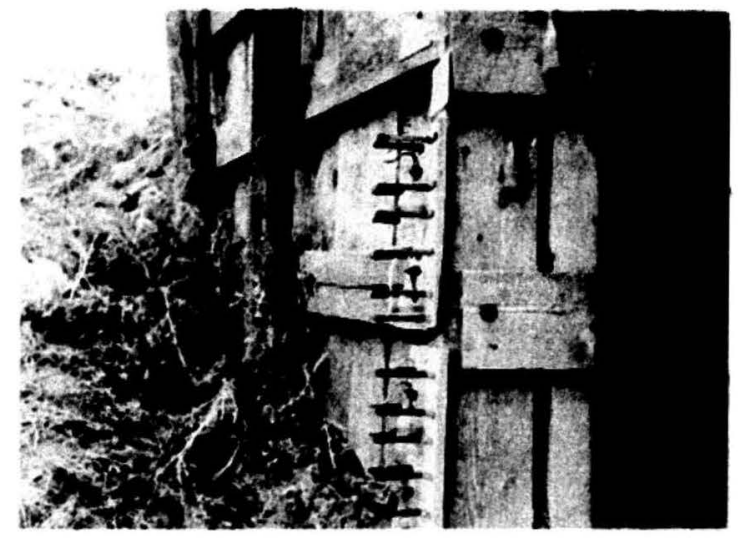

Figure 9. --8ide view of the "open" type of automatic sampler shield.

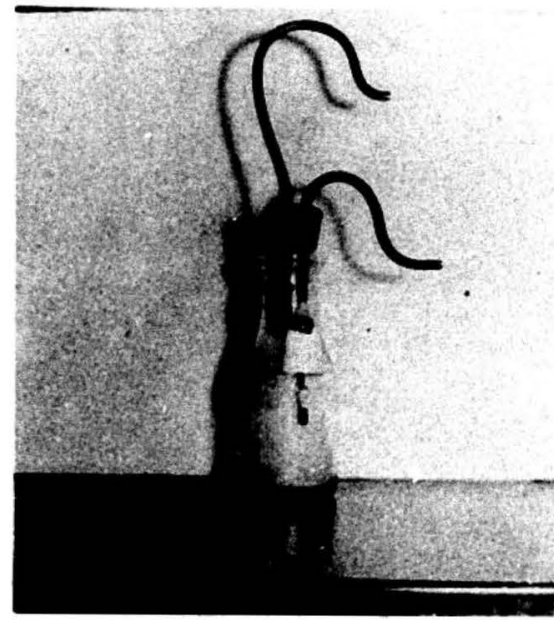

Figure 11. --Mngnetic closure in closed position on intake tube. 
that extend slightly beyond the intake tubes protect the samplers from damage by floating trees and other debris during flood stages. Heavy debris during many high stages at various str tions has caused no sampler damage thus far. Debris has not been as great a problem in the use of the automatic samplers as was originally anticipated. The variation of the size and thickness of the iron "bumpers" depends on maximum debris conditions expected at a specific sampling site.

Although any fixed sampling installation disturbs the flow conditions, probably a more accurate and representative sample is collected when the "open" type of debris shield is used.

The sampie bottle is attached to the mounting board with two pieces of hanger strap, and a bolt and wingnut are used to tighten the strap around the bottles. The bottles may be easily removed and replaced, and a bottom support is not needed for each individual bottle.

During the past 2 years the automatic sampler has been used under a wide range of flow conditions. For stockpond investigations, samples may be desired from many small tributaries and gullies during high-intensity rainfall. The runoff period is usually of such short duration that samples cannot be collected manually from all desired sampling sites; therefore, automatic samplers, installed in numerous channels and gullies, result in simultaneous sam pling of most of the inflow to the reservoir. The sampler may, under certain circumstances, be used to sample outflow from the reservoir.

The automatic sampler is particularly valuable for sampling small, flashy streams in areas remote from the field office and for sampling during high stages of major streams when floodwater or weather conditions may make the station inaccessible to field personnel.

No laboratory tests have been made to determine the effect of the intake and exhaust system on sampling characteristics and intake velocities. A few field tests were made during which the automatic sampler was used as a depth-integrating sampler; samples were collected concurrently with an automatic sampler, a U. S. D-43 sampler, and a U. S. DH-48 sampler. Suspended sediment was predominantly sand. Concentrations and particle-size distributions were very similar for samples collected with the three different samplers.

For some stream carrying suspended sediment consisting very predominantly of silt and clay, samples were collected by the automatic samplers on rising stages and with the U.S.D-43 sampler during receding stages; peak concentrations generally occurred before peak stage. Concentrations from both types of sampler were plotted on a single concentration curve. The transition from automatic sampler to the U.S. D-43 sampler showed little or no deviation.

No attempt has been made to carry out a field program in which the automatic sampler is checked against standard methods of sampling. Comparative data are insufficient to warrant any conclusions concerning the sampling characteristics of the automatic sampler.

Limitations of the automatic sampler need to be recognized: The sample is collected at or very near the water surface; at the present time (November,1956), the automatic sampler will sample only on the rising stage. Devices for sampling on the receding stage, at midpoint of depth, or at some predetermined depth below the water surface will be given limited testing in the Lincoln area during the spring runoff season.

A device for closing the intake tube immediately after the closing of the exhaust is shown in figures 10 and 11. When the rising water level inside the bottle lifts the float to within a few millimeters of the end of the intake tube, the magnetic device "jumps the gap" and provides a tight closure. The magnetic closure does not interfere with water inflow or air exhaust and provides a positive closure for the intake tube. Figure 10 shows the float in the "open" posi tion, and figure 11 shows the float in the "closed" position. The magnetic closure may be used for both the intake and the exhaust tubes, or it may be used in combination with the Davol exhaust valve. 
Rather frequent inspections and servicing may be necessary to keep the intake and exhaust tubes free of insect and spider nests and of deposits by wasps, bees, and other insects. Practically all malfunctioning of samplers in this area has been due to biological activity prior to a stream rise. Perhaps the liberal use of some type of insecticide on the samplers and installations would help solve the problem.

Further development of the automatic sampler should involve investigation of the effect of intake and exhaust design on sampling characteristics, use of the sampler on the receding stage of a stream rise, sampling at some predetermined depth below the water surface, and refinement in design of automatic closures for both intake and exhaust elements. 